\section{ПАРТИСИПАТИВНОЕ БЮДЖЕТИРОВАНИЕ И ЕГО ОСОБЕННОСТИ: ОТ ПОРТУ-АЛЕГРИ ДО СОВРЕМЕННОЙ ЕВРОПЫ}

\begin{abstract}
Аннотация. В статье анализируются особенности партисипативного бюджетирования как относительно нового эксперимента в сфрере демократии участия. Данная демократическая форма зародилась в 1989 г. в бразильском городе Порту-Алегри и затем получила распространение не только в Латинской Америке, но и на других континентах. Особое внимание уделяется странам Европы, где партисипативное бюджетирование внедрялось наиболее активно. Анализируются как положительные черты партисипативного бюджетирования, так и его возможные недостатки. По мнению автора, будучи одной из форм партисипативной демократии, партисипативное бюджетирование в то же время остается тесно привязанным к институтам представительной демократии. Инициатором его внедрения чаще всего является муниципальная исполнительная власть в целом либо ее отдельные представители, и в первую очередь главы местной администрации.
\end{abstract}

Ключевые слова: партисипативное бюджетирование, партисипативная демократия, политические партии, муниципалитеты, главы местной администрации, муниципальные советы, инвестиции, местные налоги и сборы.

\section{DOI: 10.17803/2311-5998.2021.83.7.119-126}

A. I. CHERKASOV,

Leading Research Fellow,

Human Rights Department of the Institute of State and Law, RAS,

Cand. Sci. (Law)

aligorch@yandex.ru

10, ul. Znamenka, Moscow, Russia, 119019

\title{
PARTICIPATORY BUDGETING AND ITS FEATURES: FROM PORTO ALEGRE TO MODERN EUROPE
}

\begin{abstract}
The article deals with the features of participative budgeting as a relatively new experiment in the sphere of participative democracy. It's pointed out that this democratic form was initiated in 1989 in a Brazilian city Porto Alegre and then it was spread not only over Latin America but also over other continents. Special attention is paid to the countries of Europe where participative budgeting was implemented most actively. Positive features of participative budgeting as well as its possible disadvantages are analyzed.
\end{abstract}


The author argues that participative budgeting being one of the forms of participative democracy remains at the same time closely tied to the institutions of representative democracy. The initiator of its implementation remains most often municipal executive power as a whole or its individual representatives and first of all heads of local administration.

Keywords: participative budgeting, participative democracy, political parties, municipalities, heads of local administration, municipal councils, investments, local taxes and fees. из наиболее динамично развивающихся компонентов партисипативной демократии, именуемой в отечественной литературе также «демократией участия» ${ }^{1}$. В самом общем виде ПБ определяется как «участие неизбранных граждан в определении концепции и (или) распределении публичных финнансов» ${ }^{2}$. Первоначально в научной литературе изучению подлежал лишь наиболее успешный опыт внедрения данной демократической формы. Затем, по мере распространения ПБ, начали рассматриваться самые разнообразные его примеры, как позитивные, так и негативные. Постепенно ПБ стало предметом сравнительных исследований, в рамках которых анализировались полученные результаты и делалась попытка дать ответ на вопрос о том, почему при зачастую сходных условиях ПБ более успешно развивалось в одних странах и городах и терпело неудачу в других ${ }^{3}$. Первоначально ПБ получило распространение на муниципальном уровне, и не случайно оно трактуется как «альянс между местными органами власти и гражданским обществом» ${ }^{4}$. Впоследствии ПБ стало применяться также на региональном и субмуниципальном уровнях.

Предоставляя гражданам некое новое коммуникативное пространство, ПБ предполагает их участие в распределении бюджетных средств посредством тех или иных фрорм, предусмотренных законодательством соответствующей страны (различного рода собраний, общественных советов, а также иных институтов гражданского общества). Благодаря ПБ население получает возможность представлять свои предложения по финансированию определенных проектов из муниципального бюджета и включению в него тех или иных статей. На основе таких предложений, прошедших экспертную оценку и получивших одобрение, в итоге и формируется партисипативный бюджет. В зависимости от степени финансовой автономии муниципалитета и выделяемых на эти цели ресурсов доля партисипативного бюджета обычно составляет от 2 до 10 \% бюджета муниципалитета ${ }^{5}$.

1 Руденко В. Н. Прямая демократия: модели правления, конституционно-правовые институты. Екатеринбург, 2003. С. 16-17.

2 Hope for Democracy : 25 Years of Participatory Budgeting Worldwide / ed. by N. Dias. São Brás de Alportel, 2014. P. 29.

3 См., например: Ganuza E., Baiocchi G. The Power of Ambiguity: How Participative Budgeting Travels the Globe // Journal of Public Deliberation. 2012. Vol. 8. Is. 2. Art. 8.

4 Hope for Democracy. P. 26.

5 См.: Falanga R., Lüchmann L. H. H. Participatory Budgets in Brazil and Portugal: Comparing Patterns of Dissemination // Policy Studies. 2019. Vol. 41. № 2. P. 5. 


\begin{tabular}{|c|c|}
\hline 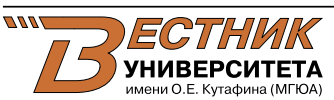 & $\begin{array}{l}\text { Черкасов А. И. } \\
\text { Партисипативное бюджетирование и его особенности: } \\
\text { от Порту-Алегри до современной Европь }\end{array}$ \\
\hline
\end{tabular}

Практика стран, использующих ПБ, как правило, варьируется с учетом местной специфики и не существует каких-то единых, застывших его форм. Может она различаться даже в рамках отдельных государств в зависимости от оперативных возможностей того или иного муниципалитета распоряжаться своим бюджетом, доли в нем местных налогов и сборов, позиции политических сил, победивших на муниципальных выборах. Неслучайно итальянский исследователь Дж. Аллегретти характеризует ПБ не столько как некую «стандартную процедуру», сколько как определенный «набор принципов, приспосабливаемых к местным условиям» и тем самым «дающих толчок процессам, которые могут носить совершенно разный характер» ${ }^{6}$.

При этом выделяются некоторые общие демократические черты ПБ: участие в указанном процессе как муниципальных органов власти, так и самих граждан, институциализация определенных форм выражения мнения населения и публичное обсуждение предполагаемых расходов, непосредственная вовлеченность граждан в отдельные инвестиционные проекты, внедрение различных фрорм отчетности по итогам исполнения партисипативного бюджета. Кроме того, подчеркивается, что ПБ должно носить не разовый характер, а «представлять собой повторяющийся процесс» ${ }^{7}$.

Партисипативное бюджетирование было впервые применено в 1989 г. в г. Порту-Алегри (столице самого южного штата Бразилии - Риу-Гранди-ду-Сул) в качестве своеобразного эксперимента со стороны левых политических сил в борьбе за мобилизацию избирателей и обеспечение большей социальной справедливости при распределении общественных благ. Данный эксперимент оказался весьма успешным не только в социальном, но и в чисто электоральном плане, принеся впоследствии его организаторам победу на муниципальных выборах.

Внедрение ПБ в Порту-Алегри означало также перестройку административных механизмов взаимоотношений муниципалитета с населением. Через ПБ начали в итоге канализироваться все социальные требования граждан, поскольку иные пути их выражения были практически закрыты. Другими словами, «получение средств из каких-либо фондов, осуществление различных проектов и инвестиций стало невозможным вне рамок партисипативного процесса» ${ }^{8}$. Административные преобразования совпали с налоговой реформой, позволившей резко увеличить поступления от местных налогов и сборов, в итоге составивших 60 \% от всего городского бюджета.

К 1997 г. ПБ использовалось уже в 103 муниципалитетах Бразилии, к 2004 г. в 261, а к 2012 г. - в $355^{9}$. По оценкам специалистов, его внедрение не только повысило эффективность предоставляемых населению услуг, но и «изменило политическую культуру гражданского общества», определив некий сдвиг в решении спорных вопросов от протеста и конфронтации к обсуждению и переговорам ${ }^{10}$.

6 Hope for Democracy. P. 52.

7 Bassoli M. Participatory Budgeting in Italy: An Analysis of (Almost Democratic) Participatory Governance Arrangements // International Journal of Urban and Regional Research. 2012. Vol. 36. № 6. P. 1185.

8 Ganuza E., Baiocchi G. Op. cit.

9 См.: Hope for Democracy. P. 157.

10 Vlahos N. The Politics of Subnational Decentralization in France, Brazil and Italy // Journal of Public Deliberation. 2013. Vol. 9. Is. 2. Art. 15. URL: https://www.publicdeliberation.net/jpd/ vol9/iss2/art15 (дата обращения: 13.11.2020). 
В 90-е гг. прошлого века ПБ получило распространение и в других странах Латинской Америки преимущественно в качестве своеобразного компонента общей стратегии левых политических сил, направленной на разрыв с традиционным для стран данного региона клиентелизмом. Кроме того, посредством подобной инновации левые стремились опровергнуть тезис о том, «что они способны лишь выступать против капиталистических институтов вместо того, чтобы их трансорормировать» ${ }^{11}$.

С конца XX - начала XXI в. ПБ стало внедряться и в иных регионах ${ }^{12}$, в значительной степени утратив свою политическую окраску. Оно начало рассматриваться в первую очередь как некий технократический инструмент со значительным демократическим потенциалом, «способный улучшить управление и обеспечить доверие к органам власти ${ }^{13}$. При этом указанный процесс стал все чаще инициироваться не столько гражданским обществом, «сколько самими публичными властями» ${ }^{14}$.

Значительное распространение ПБ получило в Европе. Если в 2000 г. ПБ функционировало лишь в шести европейских городах, то в 2005 г. - уже в 55. К 2008 г. ПБ было внедрено более чем в 100 городах Европы, а к 2010 г. - более чем в $200^{15}$, получив распространение в таких странах, как Франции, ФРГ, Бельгия, Нидерланды, Италия, Португалия, Польша, Испания, Великобритания и Швеция.

К европейским первопроходцам в указанной сфере относится, в частности, ФРГ. Партисипативное бюджетирование здесь было впервые применено в 1998 г. в небольшом городке Мёнхвайлер, расположенном в земле Баден-Вюртемберг. Вскоре его примеру последовал целый ряд других муниципалитетов, объединившихся в своеобразную партнерскую сеть «Местные власти за будущее» в целях применения новых концептуальных подходов к административной модернизации. К середине второго десятилетия XXI в. ПБ активно применялось в 96 немецких городах ${ }^{16}$.

В ФРГ в отличие от Бразилии ПБ рассматривается не столько как средство борьбы с коррупцией и обеспечения большей справедливости в перераспределении доходов, сколько как инструмент административной модернизации. Подобная модернизация реализуется посредством активизации участия населения в решении различных вопросов местной жизни и внедрения нового публичного менеджмента, превращающего граждан в первую очередь в потребителей высококачественных услуг, оказываемых в соответствии с их запросами и нуждами.

Акцент в ФРГ был сделан на том, чтобы указанный инструмент партисипативной демократии не составлял конкуренции представительной демократии и чтобы «все полномочия по принятию решений оставались в руках избранных политических представителей народа» ${ }^{17}$. Германский вариант ПБ, таким образом,

11 Ganuza E., Baiocchi G. Op. cit.

12 В настоящее время ПБ применяется в более чем 2 тыс. муниципалитетах по всему миру. См.: Falanga R., Lüchmann L. H. H. Op. cit. P. 1.

${ }^{13}$ Ganuza E., Baiocchi G. Op. cit.

${ }_{14}$ Bassoli M. Op. cit. P. 1186.

${ }^{15}$ Vlahos N. Op. cit.

${ }^{16}$ См.: Hope for Democracy. P. 287.

17 Hope for Democracy. P. 289. 


\begin{tabular}{|c|c|}
\hline 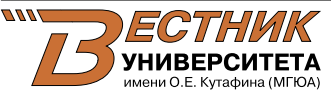 & $\begin{array}{l}\text { Черкасов А. И. } \\
\text { Партисипативное бюджетирование и его особенности: } \\
\text { от Порту-Алегри до современной Европы }\end{array}$ \\
\hline
\end{tabular}

предполагает консультирование местных властей с гражданами по бюджетным вопросам, но не принятие последними каких-либо обязывающих решений. В рамках подобной политики большое внимание местными властями уделяется разъяснительной работе и обеспечению бюджетной транспарентности. Важную роль играет также онлайн-голосование по вопросам ПБ, которое стало внедряться в ФРГ начиная с 2007 г.

Особенностью германского ПБ (за небольшими исключениями) является возможность граждан обсуждать и подавать предложения по всему муниципальному бюджету, а не только по какой-либо его отдельной - партисипативной - части, как в большинстве других стран. Причем эти предложения обычно касаются не только расходов и инвестиций, но и мер по экономии бюджетных средств.

Сама процедура ПБ в ФРГ включает в себя три стадии, которые могут быть определены как информирование, консультативное участие и отчетность. На первой стадии - стадии информирования — граждане получают разнообразную информацию касательно муниципального бюджета, расходов и доходов, а также возможных опций их участия в ПБ.

На второй стадии — консультативного участия — граждане получают возможность выдвинуть свои идеи и предложения касательно планирования муниципального бюджета, а также прореагировать на уже существующие предложения. Эти предложения обсуждаются гражданами на различных форумах в режиме онлайн либо на открытых публичных заседаниях. В итоге составляется перечень поданных предложений с учетом их конкретного рейтинга. Решения о реализации данных предложений принимает уже сам общинный совет с учетом мнения муниципальной администрации. На третьей стадии - стадии отчетности — гражданам предоставляется аргументированная информация о результатах ПБ и о том, почему были реализованы (либо, наоборот, не реализованы) те или иные предложения. В этих целях обычно составляется и публикуется отчетный доклад.

Достаточно активно ПБ применяется и в Испании. Здесь оно функционирует в Севилье, Альбасете, Кордобе, Малаге и некоторых других городах. Эксперименты по внедрению ПБ в Испании обычно проводятся по инициативе местной администрации (за исключением Альбасете) и при активном участии местных политических партий, включающих пункты о ПБ в свои политические программы. Партисипативное бюджетирование в Испании (в отличие от ФРГ) касается лишь части муниципального бюджета (от 3 \% в крупных муниципалитетах до 15 \% в небольших ${ }^{18}$ ).

В Португалии ПБ внедряется начиная с 2002 г. и в настоящее время применяется более чем в 180 муниципалитетах, что считается едва ли не «мировым рекордом ${ }^{19}$. Одной из первых европейских столиц, участвующих в указанном эксперименте, стал Лиссабон, где ПБ внедряется с 2008 г.

Процесс внедрения ПБ порой развивается достаточно нестабильно, о чем, в частности, свидетельствует опыт Италии. Партисипативное бюджетирование здесь было впервые внедрено в небольшом курортном городке Гроттамаре по инициативе политического движения «Солидарность и участие», неоднократно

${ }^{18}$ CM.: Hope for Democracy. P. 307.

${ }^{19}$ CM.: Falanga R., Lüchmann L. H. H. Op. cit. P. 9, 12.

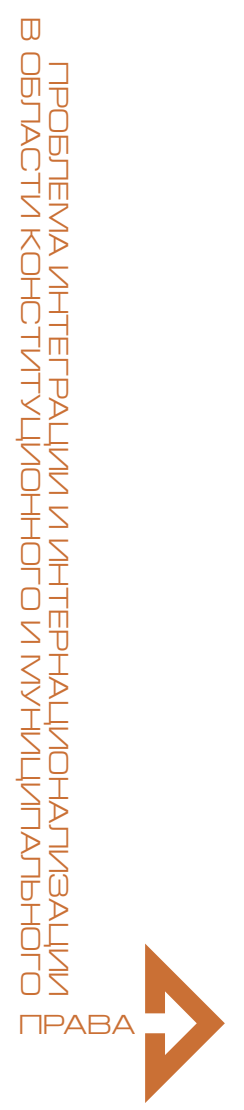


побеждавшего на муниципальных выборах начиная с 1994 г. Определенные элементы ПБ здесь стали внедряться еще в 1994 г., хотя впервые соответствующий термин был использован только после 1997 г. $^{20}$

Своего пика ПБ в Италии достигло в период с 2005 по 2010 г., получив наибольшее распространение в области Лацио, где в данном эксперименте приняли участие более 130 муниципалитетов (из ориентировочно 200 по всей стране) ${ }^{21}$. Затем в 2011 г. реализация большинства соответствующих инициатив была на определенное время приостановлена.

Опыт внедрения ПБ свидетельствует о его в целом благоприятном воздействии на политическую систему современного государства. Благодаря ПБ «укрепляются коммуникации между управленцами, политиками и гражданами» ${ }^{22}$, что способствует повышению качества публичной политики в целом. ПБ играет важную роль в качестве инструмента трансформации гражданского протеста и направления его в позитивное русло посредством выдвижения предложений, касающихся муниципальных расходов.

Партисипативное бюджетирование представляет собой также важное средство приобщения к социально-политической жизни менее зажиточных слоев населения, благодаря данной демократической инновации получающих определенные рычаги влияния на решение разнообразных вопросов местного значения.

Интеграционную роль ПБ при этом не следует переоценивать. По мнению европейских специалистов, лишь немногие города смогли улучшить положение дел в сфере обеспечения социальной справедливости посредством данной демократической процедуры ${ }^{23}$. В сфрере ПБ усиливается бюрократизация, и проводимые в его рамках встречи с заинтересованными гражданами зачастую преследуют лишь цель легитимации уже заранее принятых решений.

Будучи одной из форм партисипативной демократии, ПБ в то же время остается «тесно привязанным к институтам представительной демократии» ${ }^{24}$. Партисипативное бюджетирование, по общему мнению, остается некой «демократизацией сверху» ${ }^{25}$. Инициатором его внедрения чаще всего является муниципальная исполнительная власть в целом либо ее отдельные представители, и в первую очередь главы местной администрации. Да и сами муниципальные советы, принимающие бюджет, играют здесь далеко не последнюю роль. Именно муниципальные власти в конечном итоге устанавливают некие допустимые пределы партисипативных инициатив, регулируя каналы коммуникации с населением. Неслучайно применительно к отдельным проявлениям партисипативной демократии в научной литературе появился термин «участие по приглашению» (participation by invitation ${ }^{26}$, намекающий на недостаточную самостоятельность населения в указанных процессах.

${ }^{20}$ См.: Bassoli M. Op. cit. P. 1190.

${ }^{21}$ См.: Hope for Democracy. P. 315.

${ }^{22}$ Hope for Democracy. P. 35.

${ }^{23}$ Hope for Democracy. P. 35.

${ }^{24}$ Vlahos N. Op. cit.

${ }^{25}$ Ganuza E., Baiocchi G. Op. cit.

${ }^{26}$ Hope for Democracy. P. 48. 


\begin{tabular}{|c|c|}
\hline 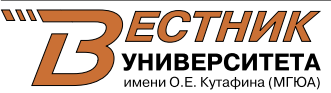 & $\begin{array}{l}\text { Черкасов А. И. } \\
\text { Партисипативное бюджетирование и его особенности: } \\
\text { от Порту-Алегри до современной Европы }\end{array}$ \\
\hline
\end{tabular}

В рамках модели ПБ, сложившейся в Бразилии, именно население определяло приоритеты, впоследствии реализуемые институтами публичной власти с максимальным уважением к мнению граждан. Применительно же к Европе речь в научной литературе все чаще идет о так называемой «рекомендательной модели» ПБ. В рамках такой модели, хотя «граждане и формулируют свои предпочтения и предложения, в конечном итоге именно публично-правовые институты принимают окончательное решение относительно того, какие именно предложения должны быть включены в перечень финансируемых проектов» ${ }^{27}$.

Европейский опыт свидетельствует о том, что ПБ зачастую представляет собой достаточно «скоропортящийся продукт». Для того чтобы ПБ оставалось жизнеспособным, необходимы постоянное проявление политической воли и его поддержка со стороны властных структур. Смена политических сил у руля муниципальной власти может иметь для ПБ крайне негативные последствия. Вполне типичными бывают случаи (например, в Италии), когда реализация ПБ прекращалась из-за того, что его сторонники, будучи ранее у власти, терпели поражение на муниципальных выборах.

Отдельными экспертами необходимость внедрения ПБ вообще ставится под сомнение применительно к правовому государству. Высказывается, в частности, мнение о том, что ПБ не должно дублировать функции представительной демократии, лишь увеличивая текущие затраты. Его следует внедрять не механически и не повсеместно, а лишь там, где существует реальный дефицит демократического участия со стороны населения, для того чтобы «можно было услышать те голоса, которые ранее были не слышны» ${ }^{28}$.

В ходе реализации ПБ выявились и некие естественные ограничения, касающиеся индивидуального участия в указанном процессе. Неформальные дебаты - основа ПБ - неизбежно подвергаются структурной трансформации и бюрократизиции. На первый план выходят организованные интересы и группы давления, обладающие соответствующим ресурсом и начинающие все больше влиять на принятие инвестиционных решений. Формировавшиеся на уровне «корней травы» пожелания в итоге «переводятся на более технократический и рациональный язык» ${ }^{29}$, не всегда понятный простым гражданам. Это приводит к так называемой «партисипативной фрустрации», формирующейся в результате возникновения некого «дисбаланса между первоначальными ожиданиями участников, надеявшихся на достижение определенного политического влияния, и их оценкой реально полученных результатов» ${ }^{30}$.

При этом не вызывает сомнений, что определенная фильтрация поступающих в рамках ПБ предложений просто необходима ввиду их, как правило, большого количества, иначе будет невозможно обеспечить разумное голосование по ним. В данном отношении показателен пример муниципалитета Лиссабона, где

${ }^{27}$ Hope for Democracy. P. 58.

${ }^{28}$ Ganuza E., Baiocchi G. Op. cit.

${ }^{29}$ Ganuza E., Baiocchi G. Op. cit.

${ }^{30}$ Fernández-Martínez J. L., García-Espín P., Jiménez-Sánchez M. Participatory Frustration: The Unintended Cultural Effect of Local Democratic Innovations // Administration \& Society. 2019. Vol. 52. № 5. P. 720. 
в 2008 г. была введена практика подачи инициативных предложений по ПБ через Интернет. Муниципалитет сразу же оказался заваленным различными предложениями. Чтобы впоследствии их стало возможным как-то рационально обсуждать, эти предложения нужно было подвергнуть анализу и сокращению. Для этого была создана специальная техническая группа, которые осмысливала и перерабатывала соответствующие инициативы. В списке обсуждаемых инициатив в конечном итоге оставалось не более $1 / 4$ или $1 / 5$ от их первоначального числа ${ }^{31}$.

В заключение следует отметить, что внедрению ПБ должны предшествовать определенные фискальные реформы, которые позволили бы увеличить доходы соответствующего муниципалитета из собственных источников. Иначе в рамках ПБ может в итоге оказаться просто нечего делить. Порой же ситуация «ставится с ног на голову» и повышение муниципальных доходов ошибочно рассматривается «как следствие внедрения партисипативного бюджетирования» ${ }^{32}$, а не наоборот.

\section{БИБЛИОГРАФИЯ}

1. Руденко В. Н. Прямая демократия: модели правления, конституционно-правовые институты. - Екатеринбург : УрО РАН, 2003. - 476 с.

2. Bassoli M. Participatory Budgeting in Italy: An Analysis of (Almost Democratic) Participatory Governance Arrangements // International Journal of Urban and Regional Research. - 2012. - Vol. 36. — № 6. - P. 1183-1203.

3. Falanga R., Lüchmann L. H. H. Participatory Budgets in Brazil and Portugal: Comparing Patterns of Dissemination // Policy Studies. - 2019. — Vol. 41. № 2. - P. 1-20.

4. Fernández-Martínez J. L., García-Espín P., Jiménez-Sánchez M. Participatory Frustration: The Unintended Cultural Effect of Local Democratic Innovations // Administration \& Society. — 2019. — Vol. 52. — № 5. - P. 718-748.

5. Ganuza E., Baiocchi G. The Power of Ambiguity: How Participative Budgeting Travels the Globe // Journal of Public Deliberation. - 2012. — Vol. 8. — Is. 2. Art. 8. - URL: http://www.publicdeliberation.net/jpd/vol8/iss2/art8.

6. Hope for Democracy : 25 Years of Participatory Budgeting Worldwide / ed. by N. Dias. - São Brás de Alportel : In Loco Association, 2014. - 491 p.

7. Vlahos N. The Politics of Subnational Decentralization in France, Brazil and Italy // Journal of Public Deliberation. - 2013. - Vol. 9. — Is. 2. - Art. 15. URL: https://www.publicdeliberation.net/jpd/vol9/iss2/art15.

${ }^{31}$ См.: Hope for Democracy. P. 60.

32 Ganuza E., Baiocchi G. Op. cit. 